\title{
10-year ASCVD risk is positively correlated with depressive symptoms in a large general population
}

\author{
Guo-Zhe Sun, Ning Ye, Shao-Jun Wu, Ying Zhou and Ying-Xian Sun*
}

\begin{abstract}
Background: To explore the potential correlation between 10-year atherosclerotic cardiovascular disease (ASCVD) risk and depressive symptoms in a general population.

Methods: A cross-sectional study involving 11,956 permanent residents of Liaoning Province in China $\geq 35$ years of age was conducted. Depressive symptoms were assessed with the Patient Health Questionnaire-9 (PHQ-9) while 10-year ASCVD risk was calculated using the tool suitable for China.

Results: Males had significantly higher 10-year ASCVD risk than females $(14.2 \pm 10.7 \%$ vs. $9.3 \pm 9.1 \% ; P<0.001)$ but lower PHQ-9 score $(2.34 \pm 3.13$ vs. $3.63 \pm 4.02 ; P<0.001)$. The mean PHQ-9 score increased significantly with advancing 10-year ASCVD risk category in both males (from 2.03 to 2.61; $P$ for trend $<0.001$ ) and females (from 3.04 to 4.61; $P$ for trend $<0.001)$, and the increasing trend was more apparent in females $(P<0.001)$. Pearson correlation analyses showed that 10-year ASCVD risk positively correlated with PHQ-9 score in both sexes (PS $<0.001)$. In multivariate linear regression analyses adjusting for confounding risk factors, the independent associations of 10-year ASCVD risk with PHQ-9 score were all significant in the total $(\beta=2.61 ; P<0.001)$, male $(\beta=1.64 ; P=0.001)$, and female subjects $(\beta=3.71 ; P<0.001)$. Further, the interaction analysis proved the impacts of 10-year ASCVD risk on PHQ-9 score were more apparent in females than males ( $\left.P_{S}<0.001\right)$.

Conclusions: The 10-year ASCVD risk was positively associated with depressive symptoms in both males and females, which was more apparent in the latter. These findings provided some novel data about the value of 10-year ASCVD risk in estimating depressive symptoms.
\end{abstract}

Keywords: 10-year ASCVD risk, Patient health Questionnaire-9, Depressive symptoms

\section{Background}

Nowadays, cardiovascular disease (CVD) has become the leading cause of death and disease burden in China and world-wide [1, 2]. Great efforts have focused on the prevention and treatment of CVD. The Framingham Risk Score has long been proved a strong predictor of developing coronary heart disease (CHD) and cardiovascular events $[3,4]$. And it's used as a simple tool to evaluate the 10-year risk of CHD to inform the initiating of primary prevention. In China, $\mathrm{Gu}$ et al. developed and validated the Chinese atherosclerotic cardiovascular disease (ASCVD) risk equation based on the China-PAR

\footnotetext{
* Correspondence: yxsun@cmu.edu.cn

Department of Cardiovascular Medicine, The First Hospital of China Medical University, 155 Nanjing Street, Heping, Shenyang 110001, Liaoning, China
}

project (Prediction for ASCVD Risk in China) in multiple contemporary Chinese cohorts [5]. This equation was suitable for China and popular-used for the prediction of ASCVD risk.

Depression has become a worldwide public health problem, especially in women $[6,7]$, which contributes to an increased risk of disability [8] and mortality [9]. The prevalence of depression is significantly higher in patients with CVD and its presence increases the risk of adverse cardiovascular events [10]. Furthermore, depression has been proved recently to be an independent risk factor for the incidence of CHD [11] or even ischemic heart disease [12]. Therefore, it's quite an important issue to define those with high possibility of depression so that we could make some strategies to control 
depressive symptoms and prevent its increased risk of ASCVD.

However, whether the 10-year ASCVD risk is also associated with depressive symptoms or not has never been reported, even though the prevalence of depression was proved to be apparently higher in patients with CVD [13]. Therefore, the current study was designed to explore the potential correlation between 10-year ASCVD risk and depressive symptoms in a large general Chinese population.

\section{Methods}

A multi-stage, random, stratified, cluster-sampling scheme was performed in this study. The details about research design, data collection and measurements have been described previously $[14,15]$. This study was approved by the Ethics Committee of China Medical University, and written consent was obtained from each participant or the proper proxy.

\section{Study population}

A total of 14,016 eligible permanent residents $\geq 35$ years of age were invited to participate in the study, and 11,956 agreed and completed the study with a response rate of $85.3 \%$. The exclusion criteria included pregnancy, malignant tumor and severe mental disorders (for example psychosis).

\section{The patient health Questionnaire-9 score}

In this study, we adopted the Patient Health Questionnaire-9 (PHQ-9) to evaluate depressive disorder, which was widely used in primary health settings as a screening instrument with good reliability and validity [16-18]. Based on the PHQ-9 tool, the total score would range from 0 to 27 , and the severity of depressive disorder was then estimated by the level of PHQ-9 score [19]. And in this study, we conducted the analyses using PHQ-9 score as continuous scale.

\section{0-year ASCVD risk}

The 10-year predicted risk of ASCVD was calculated using the equations suitable for China developed by $\mathrm{Gu}$ et al. [5]. In the equations, besides the major risk factors including age, treated or untreated systolic blood pressure (SBP), total cholesterol (TC), high density lipid cholesterol (HDL-C), current smoking, and diabetes mellitus, 4 additional variables including waist circumference, geographic region, urbanization, and family history of ASCVD were added to the equation.

\section{Definitions}

In this study, educational level was divided into three types: primary school or less, middle school, high school or more. Family income was divided into three levels
(China Yuan/year): low $(\leq 5000)$, middle $(5000-20,000)$ and high $(>20,000)$. As recommended by the Working Group on Obesity in China, obesity was defined as a body mass index (BMI) of $28.0 \mathrm{~kg} / \mathrm{m}^{2}$ or higher [20]. In accordance with the JNC 7 Guidelines [21], hypertension was defined as a $\mathrm{SBP} \geq 140 \mathrm{mmHg}$ and/or a diastolic blood pressure (DBP) $\geq 90 \mathrm{mmHg}$ and/or the use of antihypertensive medications. Diabetes mellitus was defined as a fasting blood glucose (FBG) $\geq 7.0 \mathrm{mmol} / \mathrm{L}$, and/or being on treatment by the World Health Organization criteria [22]. The National Cholesterol Education Program-Third Adult Treatment Panel criteria was followed for defining dyslipidemia (one of the following elements: $\mathrm{TC} \geq 6.21 \mathrm{mmol} / \mathrm{L}, \mathrm{HDL}-\mathrm{C}<1.03 \mathrm{mmol} / \mathrm{L}$, low density lipid cholesterol (LDL-C) $\geq 4.16 \mathrm{mmol} / \mathrm{L}$ and triglycerides (TG) $\geq 2.26 \mathrm{mmol} / \mathrm{L}$ ) [23]

\section{Statistical analysis}

Data were expressed as mean \pm standard deviation, percentage, correlation coefficient and $\beta$. Differences between groups were compared using two-tailed Student's $\mathrm{t}$-test, variance analysis or $\chi^{2}$ test as appropriate. The mean levels of PHQ-9 score among different 10-year ASCVD risk categories by sex were calculated and presented. Univariate general lineal model was used to test the interaction of sex and 10-year ASCVD risk category for PHQ-9 score. Pearson correlation analysis was performed to investigate the correlations between 10-year ASCVD risk and PHQ-9 score by sex and different medical conditions. Univariate and multivariate linear regression analyses were both conducted to identify the crude and adjusted linear associations of sex and 10-year ASCVD risk with PHQ-9 score. Further, the potential interaction of sex and 10-year ASCVD risk on PHQ-9 score was tested. All statistical analyses were performed using SPSS 17.0 software (SPSS Inc., Chicago, IL, USA), and a $P<0.05$ was considered as statistically significant.

\section{Results}

Characteristics of the study population

Of the 11,956 participants, 896 had incomplete data and were excluded from the analysis, leaving a total of 11,060 participants (5080 males and 5980 females) with a mean age of 53.9 years. Table 1 presented the sex-specific baseline characteristics of the study population. Differences between males and females were compared using two-tailed Student's t-test or $\chi^{2}$ test as appropriate. As a result, the male subjects were significantly older than females $(54.4 \pm 10.8$ vs. $53.4 \pm 10.3$; $P$ $<0.001$ ). They had significantly higher levels of SBP, DBP, FBG and education, lower levels of BMI, TC, LDL-C and income, and higher percentage of smoking and drinking (all $P \mathrm{~s}<0.05$ ), whereas, there were no significant differences in TG and HDL-C between two 
Table 1 Characteristics of the study sample

\begin{tabular}{|c|c|c|c|}
\hline Variable & Male $(n=5080)$ & Female $(n=5980)$ & $P$ value \\
\hline Age, years & $54.4 \pm 10.8$ & $53.4 \pm 10.3$ & $<0.001$ \\
\hline $\mathrm{BMI}, \mathrm{kg} / \mathrm{m}^{2}$ & $24.7 \pm 3.5$ & $24.9 \pm 3.8$ & 0.038 \\
\hline $\mathrm{SBP}, \mathrm{mmHg}$ & $143.5 \pm 22.5$ & $140.0 \pm 24.0$ & $<0.001$ \\
\hline $\mathrm{DBP}, \mathrm{mmHg}$ & $83.7 \pm 11.7$ & $80.6 \pm 11.5$ & $<0.001$ \\
\hline $\mathrm{FBG}, \mathrm{mmol} / \mathrm{L}$ & $5.95 \pm 1.63$ & $5.87 \pm 1.61$ & 0.011 \\
\hline $\mathrm{TC}, \mathrm{mmol} / \mathrm{L}$ & $5.17 \pm 1.04$ & $5.30 \pm 1.12$ & $<0.001$ \\
\hline $\mathrm{TG}, \mathrm{mmol} / \mathrm{L}$ & $1.65 \pm 1.62$ & $1.62 \pm 1.34$ & 0.266 \\
\hline $\mathrm{HDL}-\mathrm{C}, \mathrm{mmol} / \mathrm{L}$ & $1.41 \pm 0.42$ & $1.41 \pm 0.34$ & 0.683 \\
\hline $\mathrm{LDL}-\mathrm{C}, \mathrm{mmol} / \mathrm{L}$ & $2.88 \pm 0.79$ & $2.97 \pm 0.84$ & $<0.001$ \\
\hline Current smoker & $2906(57.2)$ & $980(16.4)$ & $<0.001$ \\
\hline Current drinker & $2303(45.3)$ & $171(2.9)$ & $<0.001$ \\
\hline Education & & & $<0.001$ \\
\hline$\leq$ Primary school & $2134(42.0)$ & $3405(56.9)$ & \\
\hline Middle school & $2381(46.9)$ & $2110(35.3)$ & \\
\hline$\geq$ High school & $565(11.1)$ & $465(7.8)$ & \\
\hline Family income & & & 0.016 \\
\hline Low & $683(13.4)$ & $696(11.6)$ & \\
\hline Middle & $2733(53.8)$ & $3292(55.1)$ & \\
\hline High & $1664(32.8)$ & $1992(33.3)$ & \\
\hline PHQ-9 score & $2.34 \pm 3.13$ & $3.63 \pm 4.02$ & $<0.001$ \\
\hline 10-year ASCVD risk, \% & $14.2 \pm 10.7$ & $9.3 \pm 9.1$ & $<0.001$ \\
\hline
\end{tabular}

Abbreviations: $B M I$ body mass index, ASCVD atherosclerotic cardiovascular disease, $D B P$ diastolic blood pressure, $F B G$ fasting blood glucose, $H D L-C$ high density lipid cholesterol, $L D L-C$ low density lipid cholesterol, $P H Q-9$ Patient Health Questionnaire-9, SBP systolic blood pressure, TC total cholesterol, $T G$ triglycerides. Data are expressed as mean \pm standard deviation or $n(\%)$

groups. It's worth nothing that males had significantly higher 10-year ASCVD risk than females (14.2 $\pm 10.7 \%$ vs. $9.3 \pm 9.1 \% ; P<0.001)$ but lower level of PHQ-9 score $(2.34 \pm 3.13$ vs. $3.63 \pm 4.02 ; P<0.001)$.

\section{The sex-specific PHQ-9 score by 10-year ASCVD risk category}

The mean levels of PHQ-9 score by sex and 10-year ASCVD risk category were presented in Fig. 1. Variance analysis was used to compare PHQ-9 score at different 10-year ASCVD risk categories. As a result, the mean PHQ-9 score increased significantly with advancing 10 -year ASCVD risk category in both males (from the lowest of 2.03 to the highest of 2.61 ; $P$ for trend $<0.001$ ) and females (from the lowest of 3.04 to the highest of 4.61; $P$ for trend $<0.001)$. Among each 10 -year ASCVD risk category, the mean PHQ-9 score was significantly higher in females than males (all $P_{\mathrm{s}}<0.001$ ). Further, the univariate general lineal model was used to test the interaction of sex and 10-year ASCVD risk category for PHQ-9 score, showing significant difference $(P<0.001)$.

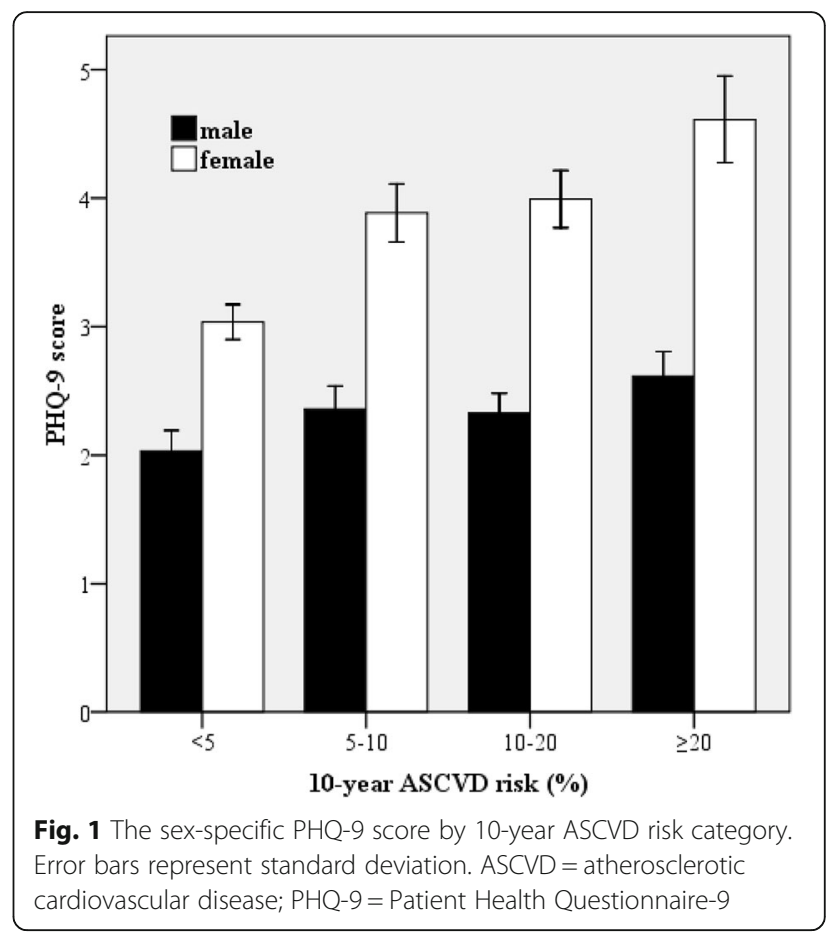

\section{Pearson correlations between 10-year ASCVD risk and PHQ-9 score}

The sex-specific pearson correlation analyses for associations between 10-year ASCVD risk and PHQ-9 score were conducted and presented in Table 2. In both sexes, 10-year ASCVD risk showed significant and positive correlations with PHQ-9 score $(P \mathrm{~S}<0.001)$. Further pearson correlation analyses presented various correlation coefficients according to different medical conditions (all Ps $<$ 0.05).

\section{Linear relationship between 10-year ASCVD risk and PHQ- 9 score}

The univariate and multivariate linear regression analyses for associations of sex and 10-year ASCVD risk with PHQ-9 score were performed and presented in Table 3. Significant correlations of sex and 10-year ASCVD risk with PHQ-9 score were observed in univariate linear regression (all $P_{\mathrm{s}}<0.001$ ). In the multivariate linear regression model, we included 10-year ASCVD risk, sex, and clinical covariates not in the 10-year ASCVD risk equation including BMI, DBP, TG, LDL-C, drinking, education and income. As a result, the independent association of 10-year ASCVD risk with $\mathrm{PHQ}-9$ score remained in the total $(\beta=2.61$; $P<0.001)$, male $(\beta=1.64 ; P=0.001)$, and female subjects $(\beta=3.71 ; P<0.001)$. The independent influence of sex on PHQ-9 score was also significant $(P$ $<0.001)$. Finally, we tested the interaction of sex and 10-year ASCVD risk in both univariate and 
Table 2 Pearson correlations between 10-year ASCVD risk and PHQ-9 score

\begin{tabular}{|c|c|c|c|c|}
\hline & \multicolumn{2}{|l|}{ Male } & \multicolumn{2}{|l|}{ Female } \\
\hline & Correlation coefficient & $P$ value & Correlation coefficient & $P$ value \\
\hline All & 0.079 & $<0.001$ & 0.131 & $<0.001$ \\
\hline \multicolumn{5}{|c|}{ Age, years } \\
\hline$<60$ & 0.051 & 0.003 & 0.087 & $<0.001$ \\
\hline$\geq 60$ & 0.062 & 0.015 & 0.064 & 0.009 \\
\hline \multicolumn{5}{|l|}{ Obesity } \\
\hline Yes & 0.126 & $<0.001$ & 0.141 & $<0.001$ \\
\hline No & 0.074 & $<0.001$ & 0.136 & $<0.001$ \\
\hline \multicolumn{5}{|c|}{ Hypertension } \\
\hline Yes & 0.101 & $<0.001$ & 0.115 & $<0.001$ \\
\hline No & 0.043 & 0.036 & 0.100 & $<0.001$ \\
\hline \multicolumn{5}{|c|}{ Diabetes } \\
\hline Yes & 0.095 & 0.033 & 0.082 & 0.036 \\
\hline No & 0.064 & $<0.001$ & 0.120 & $<0.001$ \\
\hline \multicolumn{5}{|c|}{ Dyslipidemia } \\
\hline Yes & 0.116 & $<0.001$ & 0.133 & $<0.001$ \\
\hline No & 0.045 & 0.011 & 0.121 & $<0.001$ \\
\hline
\end{tabular}

Abbreviations: $A S C V D$ atherosclerotic cardiovascular disease, $P H Q-9$ Patient Health Questionnaire-9

multivariate linear regression models, showing that sex had significant influence on the associations between 10-year ASCVD risk and PHQ-9 score with larger regression coefficients in females $\left(P_{\mathbf{s}}<0.001\right)$.

\section{Discussion}

The results of this study indicated that the mean level of PHQ-9 score increased with advancing ASCVD risk category in both sexes, and the trend was more apparent in females than males. 10-year ASCVD risk positively correlated with PHQ-9 score with larger regression

Table 3 Sex-specific linear regression analyses for associations between 10-year ASCVD risk and PHQ-9 score

\begin{tabular}{|c|c|c|c|c|}
\hline & \multicolumn{2}{|c|}{ Model 1} & \multicolumn{2}{|c|}{ Model 2} \\
\hline & $\bar{\beta}$ & $P$ value & $\bar{\beta}$ & $P$ value \\
\hline \multicolumn{5}{|l|}{$\overline{\text { All }}$} \\
\hline Sex* & 1.29 & $<0.001$ & 1.19 & $<0.001$ \\
\hline 10-year ASCVD risk & 2.17 & $<0.001$ & 2.61 & $<0.001$ \\
\hline \multicolumn{5}{|l|}{ Male } \\
\hline 10-year ASCVD risk & 2.31 & $<0.001$ & 1.64 & 0.001 \\
\hline \multicolumn{5}{|l|}{ Female } \\
\hline 10-year ASCVD risk & $5.81+$ & $<0.001$ & $3.71+$ & $<0.001$ \\
\hline
\end{tabular}

Abbreviations: ASCVD atherosclerotic cardiovascular disease, $P H Q-9$ Patient Health Questionnaire-9

Model 1: univariate linear regression model; Model 2: multivariate linear regression model including 10-year ASCVD risk, gender, body mass index, diastolic blood pressure, triglyceride, low density lipid cholesterol, drinking, education, and income

*: " 0 " for male and " 1 " for female in the analysis

$t: P<0.001$ for gender difference coefficients in females. Sex had significant effects not only on PHQ-9 score but also on the associations of 10-year ASCVD risk and PHQ-9 score. These findings firstly provide some data about associations between 10-year ASCVD risk and depressive symptoms in a general population.

Recent studies demonstrated that depression was positively associated with both CVD incidence among healthy individuals [24] and adverse cardiovascular events among patients with established CVD [25, 26]. Therefore, great efforts were conducted to make clear of the epidemiological characteristics of depression and to make population-based prevention strategies. Accordingly, depression was reported to be quite common among patients with CVD [27]. Similarly, the prevalence of depression was significantly higher in patients with heart failure [28], hypertension [29], diabetes [30], stroke [31] than healthy population. Thus, high prevalence of depression was presented among patients with CVD. Now, our data firstly indicated that depressive symptoms was more common in subjects with higher 10-year predicted risk of ASCVD, suggesting that screening and controlling of the potential depressive symptoms were needed among subjects with high risk of ASCVD.

The equation found by $\mathrm{Gu}$ et al. has been used widely as a tool suitable for China to assess the incidence risk of ASCVD, which was calculated based on age, treated or untreated SBP, TC, HDL-C, current smoking, diabetes mellitus, waist circumference, geographic region, urbanization and family history of ASCVD [5]. Previous 
studies have demonstrated that advancing age [7, 32], smoking [33], low HDL-C [34] and high SBP [28] were mostly correlated with depression although serum TC and depression might be inversely related [35]. Therefore, depression and ASCVD have some co-existing risk factors, which might partially explain the positive relationship between 10-year predicted risk and depressive symptoms in our current study. Further, health behaviors, inflammatory processes and heart rate variability might be the potential mechanisms that actually mediated the incidence of ASCVD and depression [36, 37].

However, some limitations are existing in our study. First, there was only PHQ-9 tool assessing depressive symptoms but no clinical diagnosis of depression by a psychiatrist. Second, the number of participants in some subgroups was relatively small so that an unintentional bias might be brought. Third, the current study was part of NCRCHS, and only rural Chinese subjects $\geq 35$ years of age were included. In addition, covariates in the current study were relatively limited and some other possible covariates might give a bias.

\section{Conclusions}

10-year ASCVD risk was positively associated with depressive symptoms in both males and females. And more apparent impacts of 10-year ASCVD risk on PHQ-9 score were observed in females. These findings provided some novel insights into the value of 10-year ASCVD risk in estimating depressive symptoms. Much attention should be paid to depressive disorders among subjects with high 10-year ASCVD risk.

\section{Abbreviations \\ ASCVD: atherosclerotic cardiovascular disease; BMI: body mass index; CHD: coronary heart disease; CVD: cardiovascular disease; DBP: diastolic blood pressure; FBG: Fasting blood glucose; HDL-C: high density lipid cholesterol; LDL-C: low density lipid cholesterol; PHQ-9: Patient Health Questionnaire-9; SBP: systolic blood pressure; TC: total cholesterol; TG: triglycerides}

\section{Acknowledgements}

We would like to thank Professor Liqiang Zheng for data collection and data management and Professor Zhao Li for support on the project.

\section{Funding}

This study was founded by the National Science and Technology Support Program of China (No. 2012BAJ18B08-7) and Liaoning Research Center for Translational Medicine of Cardiovascular Disease (No. 2014225017).

\section{Availability of data and materials}

The datasets generated and analyzed during the current study are not publicly available, and we do not wish to share our data since the whole NCRCHS study is at the further follow-up stage and the data is still not open. But they are available from the corresponding author on reasonable request.

\section{Authors' contributions}

GZS participated in the investigation, collected the data, performed the statistical analysis and prepared the draft of the manuscript. NY participated in the data collection. SJW coordinated the statistical analysis and revised the manuscript. YZ participated in the study design and supervised the data collection during investigation. YXS conceived the study design, reviewed the manuscript and served as the guarantor for the paper. All authors approved the final manuscript.

\section{Authors' information}

Guo-Zhe Sun (gzhsun66@163.com), Ning Ye (yening_cmu@163.com), ShaoJunWu (1145167664@qq.coom), Ying Zhou (zhouying8111003@126.com), and Ying-Xian Sun (yxsun@cmu.edu.cn). All the authors were from the Department of Cardiovascular Medicine in the First Hospital of China Medical University.

\section{Ethics approval and consent to participate}

The study was approved by the Ethics Committee of China Medical University (Shenyang, China). All procedures were performed in accordance with the ethical standards. Written consent was obtained from all participants. In the case of an illiterate participant, written informed consent was obtained from the appropriate legal proxy.

\section{Consent for publication}

Not applicable.

\section{Competing interests}

The authors declare that they have no competing interests.

\section{Publisher's Note}

Springer Nature remains neutral with regard to jurisdictional claims in published maps and institutional affiliations.

Received: 29 November 2018 Accepted: 11 April 2019

Published online: 26 April 2019

\section{References}

1. GBD 2013 Mortality and Causes of Death Collaborators. Global, regional, and national age-sex specific all-cause and cause-specific mortality for 240 causes of death, 1990-2013: a systematic analysis for the Global Burden of Disease Study 2013. Lancet. 2015;385:117-71.

2. Zhou M, Wang H, Zhu J, Chen W, Wang L, Liu S, et al. Cause-specific mortality for 240 causes in China during 1990-2013: a systematic subnational analysis for the global burden of disease study 2013. Lancet. 2016:387:251-72.

3. Wannamethee SG, Shaper AG, Lennon L, Morris RW. Metabolic syndrome vs Framingham risk score for prediction of coronary heart disease, stroke, and type 2 diabetes mellitus. Arch Intern Med. 2005;165:2644-50.

4. Sara JD, Lennon RJ, Gulati R, Singh M, Holmes DR Jr, Lerman LO, et al. Utility of the Framingham risk score in predicting secondary events in patients following percutaneous coronary intervention: a time-trend analysis. Am Heart J. 2016:172:115-28.

5. Yang X, Li J, Hu D, Chen J, Li Y, Huang J, et al. Predicting the 10-year risks of atherosclerotic cardiovascular disease in Chinese population: the China-PAR project (prediction for ASCVD risk in China). Circulation. 2016;134:1430-40.

6. Alonso J, Angermeyer MC, Bernert S, Bruffaerts R, Brugha TS, Bryson H, et al. Prevalence of mental disorders in Europe: results from the European study of the epidemiology of mental disorders (ESEMeD) project. Acta Psychiatr Scand Suppl. 2004;420:21-7.

7. Zhou X, Bi B, Zheng L, Li Z, Yang H, Song H, et al. The prevalence and risk factors for depression symptoms in a rural Chinese sample population. PLoS One. 2014;9:e99692.

8. Murray CJ, Lopez AD. Alternative projections of mortality and disability by cause 1990-2020: global burden of disease study. Lancet. 1997;349:1498-504.

9. Chesney E, Goodwin GM, Fazel S. Risks of all-cause and suicide mortality in mental disorders: a meta-review. World Psychiatry. 2014;13:153-60.

10. Whooley MA. Depression and cardiovascular disease: healing the brokenhearted. JAMA. 2006;295:2874-81.

11. O'Neil A, Fisher AJ, Kibbey KJ, Jacka FN, Kotowicz MA, Williams LJ, et al. Depression is a risk factor for incident coronary heart disease in women: an 18-year longitudinal study. J Affect Disord. 2016;196: $117-24$.

12. Chen S, Fang Y, Chiu H, Fan H, Jin T, Conwell Y. Validation of the nine-item patient health questionnaire to screen for major depression in a Chinese primary care population. Asia-Pac Psychiatry. 2013;5:61-8. 
13. Huffman JC, Celano CM, Beach SR, Motiwala SR, Januzzi JL. Depression and cardiac disease: epidemiology, mechanisms, and diagnosis. Cardiovasc Psychiatry Neurol. 2013;2013:695925.

14. Sun GZ, Ye N, Zhang NJ, Li Y, Chen S, Chang Y, et al. Association between $\mathrm{CHADS}_{2}$ score, depressive symptoms, and quality of life in a general population. BMC Psychiatry. 2017:17:80.

15. Sun GZ, Guo L, Wang J, Ye N, Wang XZ, Sun YX. Association between hyperuricemia and atrial fibrillation in rural China: a cross-sectional study. BMC Cardiovasc Disord. 2015;15:98

16. Lowe B, Kroenke K, Herzog W, Grafe K. Measuring depression outcome with a brief self-report instrument: sensitivity to change of the patient health questionnaire (PHQ-9). J Affect Disord. 2004;81:61-6.

17. Kroenke K, Spitzer RL, Williams JB. The PHQ-9: validity of a brief depression severity measure. J Gen Intern Med. 2001;16:606-13.

18. Liu N, Pan XF, Yu C, LV J, Guo Y, Bian Z, et al. Association of Major Depression with Risk of ischemic heart disease in a mega-cohort of Chinese adults: the China Kadoorie biobank study. J Am Heart Assoc. 2016;5: e004687.

19. Manea L, Gilbody S, McMillan D. Optimal cut-off score for diagnosing depression with the patient health questionnaire (PHQ-9): a meta-analysis. Can Med Assoc J. 2012;184:E191-6.

20. Zhou BF. Effect of body mass index on all-cause mortality and incidence of cardiovascular diseases--report for meta-analysis of prospective studies open optimal cut-off points of body mass index in Chinese adults. Biomed Environ Sci. 2002;15:245-52.

21. Chobanian AV, Bakris GL, Black HR, Cushman WC, Green LA, Izzo JL Jr, et al. The seventh report of the joint National Committee on prevention, detection, evaluation, and treatment of high blood pressure: the JNC 7 report. JAMA. 2003;289:2560-72.

22. World Health Organization and International Diabetes Fedaration. Definition and diagnosis of diabetes mellitus and intermediate hyperglycemia: report of a WHO/IDF consultation. Geneva: WHO; 2006. p. 1-3.

23. Expert Panel on Detection, Evaluation, and Treatment of High Blood Cholesterol in Adults. Executive summary of the third report of the National Cholesterol Education Program (NCEP) expert panel on detection, evaluation, and treatment of high blood cholesterol in adults (adult treatment panel III). JAMA. 2001;285:2486-97.

24. Lett HS, Blumenthal JA, Babyak MA, Sherwood A, Strauman T, Robins C, et al. Depression as a risk factor for coronary artery disease: evidence, mechanisms, and treatment. Psychosom Med. 2004;66:305-15.

25. Barth J, Schumacher M, Herrmann-Lingen C. Depression as a risk factor for mortality in patients with coronary heart disease: a meta-analysis. Psychosom Med. 2004;66:802-13.

26. Nielsen TJ, Vestergaard M, Christensen B, Christensen KS, Larsen KK. Mental health status and risk of new cardiovascular events or death in patients with myocardial infarction: a population-based cohort study. BMJ Open. 2013;3:e003045.

27. Thombs BD, Bass EB, Ford DE, Stewart KJ, Tsilidis KK, Patel U, et al. Prevalence of depression in survivors of acute myocardial infarction. J Gen Intern Med. 2006;21:30-8.

28. Rutledge T, Reis VA, Linke SE, Greenberg BH, Mills PJ. Depression in heart failure a meta-analytic review of prevalence, intervention effects, and associations with clinical outcomes. J Am Coll Cardiol. 2006:48:1527-37.

29. Li Z, Li Y, Chen L, Chen P, Hu Y. Prevalence of depression in patients with hypertension: a systematic review and meta-analysis. Med. 2015:94:e1317.

30. Anderson RJ, Freedland KE, Clouse RE, Lustman PJ. The prevalence of comorbid depression in adults with diabetes: a meta-analysis. Diabetes Care. 2001;24:1069-78

31. Fei K, Benn EK, Negron R, Arniella G, Tuhrim S, Horowitz CR. Prevalence of depression among stroke survivors: racial-ethnic differences. Stroke. 2016:47:512-5.

32. Risal A, Manandhar K, Linde M, Steiner TJ, Holen A. Anxiety and depression in Nepal: prevalence, comorbidity and associations. BMC Psychiatry. 2016;16:102.

33. Kim NH, Kim HC, Lee JY, Lee JM, Suh I. Association between environmental tobacco smoke and depression among Korean women. BMJ Open. 2015;5: e007131.

34. Lehto SM, Hintikka J, Niskanen L, Tolmunen T, Koivumaa-Honkanen $\mathrm{H}_{\text {, }}$ Honkalampi K, et al. Low HDL cholesterol associates with major depression in a sample with a 7-year history of depressive symptoms. Prog NeuroPsychopharmacol Biol Psychiatry. 2008;32:1557-61.
35. Shin JY, Suls J, Martin R. Are cholesterol and depression inversely related? A meta-analysis of the association between two cardiac risk factors. Annals Behav Med. 2008;36:33-43.

36. Kim D, Kubzansky LD, Baccarelli A, Sparrow D, Spiro A 3rd, Tarantini L, et al. Psychological factors and DNA methylation of genes related to immune/ inflammatory system markers: the VA normative aging study. BMJ Open. 2016;6:e009790

37. Elderon L, Whooley MA. Depression and cardiovascular disease. Prog Cardiovasc Dis. 2013:55:511-23.

\section{Ready to submit your research? Choose BMC and benefit from:}

- fast, convenient online submission

- thorough peer review by experienced researchers in your field

- rapid publication on acceptance

- support for research data, including large and complex data types

- gold Open Access which fosters wider collaboration and increased citations

- maximum visibility for your research: over $100 \mathrm{M}$ website views per year

At BMC, research is always in progress.

Learn more biomedcentral.com/submissions 